\title{
ArgR is an essential local transcriptional regulator of the arcABC operon in Streptococcus suis and is crucial for biological fitness in an acidic environment
}

Correspondence

Ralph Goethe

ralph.goethe@tiho-hannover.de

Received 29 June 2010

Revised 23 September 2010

Accepted 7 October 2010

\author{
Marcus Fulde, ${ }^{1} \dagger$ Joerg Willenborg, ${ }^{1} \dagger$ Astrid de Greeff, ${ }^{2}$ Laurentiu Benga, ${ }^{1}$ \\ Hilde E. Smith, ${ }^{2}$ Peter Valentin-Weigand ${ }^{1}$ and Ralph Goethe ${ }^{1}$ \\ ${ }^{1}$ Institut für Mikrobiologie, Zentrum für Infektionsmedizin, Stiftung Tierärztliche Hochschule \\ Hannover, 30173 Hannover, Germany \\ ${ }^{2}$ Animal Sciences Group (ASG), Wageningen UR, PO Box 65, 8200 AB Lelystad, The Netherlands
}

\begin{abstract}
Streptococcus suis is one of the most important pathogens in pigs and can also cause severe infections in humans. Despite its clinical relevance, very little is known about the factors that contribute to its virulence. Recently, we identified a new putative virulence factor in $S$. suis, the arginine deiminase system (ADS), an arginine catabolic enzyme system encoded by the arc $A B C$ operon, which enables $S$. suis to survive in an acidic environment. In this study, we focused on ArgR, an ADS-associated regulator belonging to the ArgR/AhrC arginine repressor family. Using an $\arg R$ knockout strain we were able to show that $\operatorname{ArgR}$ is essential for $\operatorname{arc} A B C$ operon expression and necessary for the biological fitness of $S$. suis. By CDNA expression microarray analyses and quantitative real-time RT-PCR we found that the $\operatorname{arc} A B C$ operon is the only gene cluster regulated by ArgR, which is in contrast to the situation in many other bacteria. Reporter gene analysis with gfp under the control of the $\operatorname{arc} A B C$ promoter demonstrated that $A r g \mathrm{R}$ is able to activate the $\operatorname{arc} A B C$ promoter. Electrophoretic mobility shift assays with fragments of the $\operatorname{arc} A B C$ promoter and recombinant $\mathrm{ArgR}$, and chromatin immunoprecipitation with antibodies directed against $\mathrm{ArgR}$, revealed that $\mathrm{ArgR}$ interacts with the $\operatorname{arc} A B C$ promoter in vitro and in vivo by binding to a region from -147 to $-72 \mathrm{bp}$ upstream of the transcriptional start point. Overall, our results show that in $S$. suis, ArgR is an essential, system-specific transcriptional regulator of the ADS that interacts directly with the $\operatorname{arc} A B C$ promoter in vivo.
\end{abstract}

\section{INTRODUCTION}

The regulation of arginine metabolism is mediated by the members of the ArgR/AhrC family of transcriptional regulators. These regulators and their cognate target sites are highly conserved among very diverse organisms, including Gram-positive and Gram-negative bacteria. In general, ArgR/AhrC proteins regulate their target genes by binding to operator sites, leading to repression of arginine biosynthetic genes and activation of catabolic genes in the presence of arginine (Gardan et al., 1995; Grandori et al.,

†These authors contributed equally to this work.

Abbreviations: ADS, arginine deiminase system; CCR, carbon catabolite repression; EMSA, electrophoretic mobility shift assay; qRT-PCR, quantitative RT-PCR; 5'-RACE, rapid amplification of 5' cDNA ends.

The microarray data discussed in this paper are available from ArrayExpress under accession number E-MEXP-2945.

Two supplementary tables, showing the primers used in this study and genes up- or downregulated by ArgR, are available with the online version of this paper.
1995; Kiupakis \& Reitzer, 2002; Klingel et al., 1995; Lu \& Abdelal, 1999; Makarova et al., 2001). Furthermore, it is now clear that in Escherichia coli, ArgR not only is involved in regulation of arginine metabolism but also regulates various genes of arginine transport (Caldara et al., 2006).

Mechanisms for arginine catabolism differ among organisms (Blakemore \& Canale-Parola, 1976; Broman et al., 1978; Floderus et al., 1990; Mercenier et al., 1980). A widely distributed system in many bacteria, including homofermentative cocci, is the arginine deiminase system (ADS). It allows degradation of arginine into ornithine, ammonia and carbon dioxide catalysed by arginine deiminase (ArcA), ornithine carbamoyltransferase (ArcB) and carbamate kinase (ArcC) (Barcelona-Andrés et al., 2002; Burne et al., 1989; Champomier Vergès et al., 1999; Chaussee et al., 2003; Crow \& Thomas, 1982; Zuñiga et al., $2002 \mathrm{~b})$. Expression of the ADS is often closely connected to carbon metabolism via carbon catabolite repression (CCR) (Liu et al., 2008; Zeng et al., 2006). The generation of ATP by the conversion of arginine to ornithine plays an 
important role in supplying the bacteria with energy during nutrient starvation. Furthermore, the ADS facilitates the evasion of acid stress by production of ammonium, and it supplies carbamoyl phosphate, which is essential for de novo synthesis of pyrimidines (van den Hoff et al., 1995).

In many bacteria, the ADS has been shown to be regulated by members of the ArgR/AhrC family. In addition, the CCR regulator protein CcpA contributes to its regulation as a repressor, whereas the members of the CRP/FNR family of transcriptional regulators have been shown to positively regulate ADS expression (Barcelona-Andrés et al., 2002; Dong et al., 2004; Maghnouj et al., 2000; Zuñiga et al., 2002a).

Streptococcus suis is a Gram-positive, facultatively anaerobic pathogen that colonizes mainly the upper respiratory tract of swine. It is endemic in nearly all pig-producing industries and causes high economic losses due to meningitis, septicaemia, arthritis, endocarditis and bronchopneumonia. As a zoonotic agent, S. suis can cause meningitis and sepsis in humans (Arends \& Zanen, 1988; Chanter et al., 1993; Clifton-Hadley \& Alexander, 1980; Gottschalk et al., 2010; Rosenkranz et al., 2003).

Little is known about the virulence factors or protective antigens of S. suis. Previously, we identified two proteins of the S. suis ADS which were temperature-induced and expressed on the streptococcal surface (Winterhoff et al., 2002). Furthermore, we were able to show that the ADS is inducible by arginine and $\mathrm{O}_{2}$ tension, is subject to CCR, and contributes to survival under acidic conditions (Gruening et al., 2006). The arginine catabolic genes $\operatorname{arc} A$, $\operatorname{arcB}$ and $\operatorname{arc} C$, which are transcribed polycistronically, are clustered together with the genes for a putative arginine/ornithine antiporter $(\operatorname{arcD})$, a putative Xaa-His dipeptidase $(\operatorname{arcT})$, and a putative endo- $\beta$-galactosidase $\mathrm{C}$ $(\operatorname{arcH})$. The ADS gene cluster is bounded by the genes of two putative transcriptional regulators, the FNR-like protein of S. suis (FlpS) at the $5^{\prime}$ end of the $\operatorname{arcABC}$ operon, and $\operatorname{argR}$, encoding a repressor of the ArgR/AhrC family (ArgR) at the $3^{\prime}$ end of $\operatorname{arcH}$.

In the present study we found that in S. suis, $\operatorname{ArgR}$ is essential for $\operatorname{arc} A B C$ operon expression activity and specifically regulates the $\operatorname{arc} A B C$ operon by directly interacting with its promoter. Furthermore, we provide evidence that ArgR is essential for the biological fitness of S. suis.

\section{METHODS}

Bacterial strains and growth conditions. The highly virulent serotype 2 strain 10 and its capsule-deficient mutant strain 10 $\Delta c p s \mathrm{EF}:: s p c \mathrm{R}$ were used as parental strains (Smith et al., 1999). Bacteria were routinely grown in Todd-Hewitt Broth (Becton Dickinson Diagnostics) or, if indicated, in a tryptone-yeast (TY) minimal medium with $10 \mathrm{mM}$ galactose as a non-repressive sugar. Subculturing was performed on Columbia blood agar base (Difco) containing $6 \%(\mathrm{v} / \mathrm{v})$ sheep blood overnight at $37{ }^{\circ} \mathrm{C}$. To analyse the external $\mathrm{pH}$ during bacterial growth, bacteria were grown in TY medium overnight. Then, streptococci were adjusted to $\mathrm{OD}_{600} 0.02$, and the $\mathrm{pH}$ was monitored at the indicated time points. E. coli was subcultured and maintained on Luria-Bertani agar plates. If required, antibiotics were added at the following concentrations: spectinomycin at $100 \mu \mathrm{g} \mathrm{ml}^{-1}$ (S. suis) and $50 \mu \mathrm{g} \mathrm{ml}^{-1}$ (E. coli), erythromycin at $1 \mu \mathrm{g} \mathrm{ml}^{-1}$ (S. suis) and $300 \mu \mathrm{g} \mathrm{ml}^{-1}$ (E. coli), and ampicillin at $100 \mu \mathrm{g}$ $\mathrm{ml}^{-1}$ (E. coli).

DNA techniques. Chromosomal S. suis DNA was prepared according to standard procedures (Sambrook et al., 1989). Plasmid DNA was purified with the NucleoSpin Plasmid kit (Macherey-Nagel) according to the manufacturer's instructions. If not stated otherwise, all restriction enzymes were purchased from New England Biolabs.

Rapid amplification of $5^{\prime}$ cDNA ends (5'-RACE). The transcriptional start point of the $\operatorname{arcABC}$ operon was determined by RACE with a 5'RACE kit (Invitrogen). Briefly, cDNA was synthesized from DNase I-treated (Ambion) RNA of S. suis strain 10 with primer GSP2 (Supplementary Table S1) according to the manufacturer's instructions. After tailing, PCR was performed with the primer pair ADSprimerext/AAP, followed by a nested PCR with primer pair ADSprimerext/AUAP (Supplementary Table S1). Sequencing was performed by Seqlab Laboratories, Göttingen, Germany.

Production and purification of recombinant ArgR. Recombinant ArgR was produced as a $6 \times$ His-tagged fusion protein in E. coli with the QIAexpress paired $p$ REP4- $p$ QE plasmid system (Qiagen). Briefly, $\operatorname{argR}$ was amplified by PCR from chromosomal DNA with the specific oligonucleotide primer pair ArgR-PstI/ArgR-SphI (Supplementary Table S1) and cloned into the PstI/SphI-digested expression vector $p \mathrm{QE} 30$. The resulting plasmid, $p \mathrm{QE} 30 \operatorname{argR}$, was introduced into E. coli strain M15[ $p$ REP4] (Qiagen). IPTG-induced recombinant ArgR was purified by $\mathrm{Ni}^{2+}$-nitrilotriacetic acid affinity chromatography according to the manufacturer's instructions (Qiagen). A polyclonal antiserum against recombinant ArgR was raised in a New Zealand white rabbit (Charles River Laboratories).

Electrophoretic mobility shift assay (EMSA). To localize the ArgR-binding site in vitro, different fragments of the promoter region of the $\operatorname{arcABC}$ operon were generated by PCR with the forward primers 1-EMSA, 2-EMSA, 3-EMSA and 4-EMSA in combination with the reverse primer EMSA-rev (Supplementary Table S1). The DNA fragments were purified with the QIAquick PCR Purification kit (Qiagen) according to the manufacturer's instructions. Then, $200 \mathrm{ng}$ DNA was incubated with or without $1 \mu \mathrm{g}$ recombinant ArgR and incubated in binding buffer $(10 \mathrm{mM}$ Tris/ $\mathrm{HCl}, \mathrm{pH} 7.5,50 \mathrm{mM}$ DTT, $5 \%, \mathrm{v} / \mathrm{v}$, glycerol, $10 \mathrm{mM} \mathrm{NaCl}, 1 \mathrm{mM} \mathrm{MgCl}_{2}$ ) for $1 \mathrm{~h}$ at room temperature. Protein-DNA complexes were separated electrophoretically in a native $5 \%$ polyacrylamide gel and visualized by ethidium bromide staining.

Mutagenesis. The $\operatorname{arcABC}$ operon and the ADS-associated regulator ArgR were inactivated by insertion mutagenesis in S. suis strains 10 and $10 \Delta c p s \mathrm{EF}: s p c \mathrm{R}(10 \Delta c p s \mathrm{EF})$. Briefly, the gene encoding the putative arginine regulator $\mathrm{ArgR}$ was amplified from the streptococcal genome with the primers $\operatorname{argRKOlin}$ and $\operatorname{argRKOrec}$ (Supplementary Table S1) and subsequently introduced into the cloning vector pCR2.1-TOPO (Invitrogen). The resulting plasmid, $p$ TOPO- $\operatorname{argR}$, was linearized by HincII. Then, the PvuII-released erythromycinresistance cassette derived from vector pICerm was introduced to disrupt $\operatorname{argR}$. Electroporation of the parental strains was performed as previously described (Gruening et al., 2006; Smith et al., 1995). For inactivation of the $\operatorname{arc} A B C$ operon, the plasmid pGEMAD carrying $\operatorname{arc} A B C$ was linearized with the restriction enzyme EcoRV and the operon was disrupted by insertion of an erythromycin-resistance cassette in $\operatorname{arcA}$. The resulting plasmid was transformed into $S$. suis 
strains 10 and $10 \Delta c p s E F$. Mutants were controlled by PCR and immunoblot analysis.

Construction of $\boldsymbol{g} \boldsymbol{f p}$ reporter strains. For transcriptional fusion of the $\operatorname{arc} A B C$ promoter to the GFP reporter protein, a $2836 \mathrm{bp}$ fragment containing the promoter-operator region of the $\operatorname{arc} A B C$ operon and the $\operatorname{arcA}$ gene was amplified with the primer pair IFL/IFR (Supplementary Table S1) from the streptococcal genome and subsequently cloned into pGEMT-Easy (Promega). The resulting plasmid, $p$ IFGEMT-Easy, was used as template for inverse PCR using the primer pair Backbone1-HindIII/Backbone2-KpnI (Supplementary Table S1), and the PCR product was digested with the respective restriction enzymes. In parallel, the promoterless $g f p$ allele $g f p m u t 3 *$ was amplified from the Gram-positive shuttle vector pDL278$g f p m u t 3 *$ with the primer pair $g f p-H i n d I I I / g f p-K p n I$ (Supplementary Table S1) and digested with the same enzymes inserted into the PCR-amplified vector backbone. The resulting fragment containing the promoter- $g f p$ fusion was subcloned into the shuttle vector pGA14 spc (Smith et al., 1995) to obtain the reporter plasmid $p \mathrm{GAl} 4_{\mathrm{spc}}-\mathrm{Parc} 709-g f p$. Reporter plasmids carrying either the truncated $\operatorname{arc} A B C$ promoter fusion ( $p \mathrm{GA1} 4_{\mathrm{spc}}-\mathrm{P} a r c 187-g f p$ ) or no promoter fusion $\left(p \mathrm{GA} 14_{\mathrm{spc}^{-}} g f p\right)$ were generated in the same way using different primers (Supplementary Table S1) for inverse PCR. Reporter plasmids were introduced into S. suis strain 10 or strain $10 \Delta \operatorname{argR}$ by electro-transformation. Transformants were screened by plating onto spectinomycin-containing blood agar plates and plasmid isolation with subsequent EcoRI restriction digestion. For promoter studies, bacteria were grown overnight in TY medium supplemented with $10 \mathrm{mM}$ galactose. Then, bacterial suspensions were adjusted to $\mathrm{OD}_{600}$ 0.02 in the same medium and cultured at $37{ }^{\circ} \mathrm{C}$ for $\sim 8 \mathrm{~h}$ to $\mathrm{OD}_{600}$ 0.2 . One millilitre of bacterial culture was harvested by centrifugation, washed twice with PBS and resuspended in $1 \mathrm{ml}$ PBS. One hundred microlitres of the suspension was used for $g f p$ measurements. Fluorescence was measured in a fluorescence reader (excitation, $485 \mathrm{~nm}$; emission, $535 \mathrm{~nm}$ ). Relative fluorescence values were calculated by subtracting extinction from the PBS background. Experiments were carried out in triplicate and repeated at least twice.

Chromatin immunoprecipitation. For ChIP analysis the wild-type strain 10 and strain $10 \Delta$ argR were grown in THB medium to $\mathrm{OD}_{600}$ 0.3 and 0.9 , representing the mid-exponential and early stationary growth phases, respectively. The in vivo cross-linking of proteinbound DNA was done with $1 \%$ formaldehyde $(\mathrm{v} / \mathrm{v})$ for $5 \mathrm{~min}$ at room temperature and then stopped by addition of glycine in a final concentration of $0.125 \mathrm{M}$. The bacterial cells were collected by centrifugation at $4000 \mathrm{~g}$ and $4{ }^{\circ} \mathrm{C}$, and washed twice with ice-cold $50 \mathrm{mM}$ Tris ( $\mathrm{pH} \mathrm{8.0)}$. The pellet was resuspended in cell lysis buffer [50 mM Tris/HCl, pH 8.0, $1 \%$ SDS, $10 \mathrm{mM}$ EDTA, $1 \mathrm{mM} \mathrm{4-(2-}$ aminoethyl) benzenesulfonyl fluoride hydrochloride (AEBSF) (Merck Biosciences)] and $1 \times$ protease inhibitor for bacterial cell extracts (Sigma), and was ruptured using the FastPrep instrument (Qbiogene) three times for $45 \mathrm{~s}$ at highest intensity. Bacterial chromatin was sheared by ultrasonic disintegration. The cleared lysates were diluted fivefold in ChIP dilution buffer (16.5 mM Tris/ $\mathrm{HCl}, \mathrm{pH}$ 8.0, $1.2 \mathrm{mM}$ EDTA, $167 \mathrm{mM} \mathrm{NaCl}, 1.1 \%$ Triton X-100, $0.01 \%$ SDS, $1 \mathrm{mM}$ AEBSF). Then, $25 \mu \mathrm{g}$ ChIP lysate chromatin was mixed with $30 \mu \mathrm{l}$ salmon sperm DNA/protein-A agarose matrix and $10 \mu \mathrm{l}$ polyclonal rabbit anti-rArgR ( $\alpha$-rArgR) antiserum or preimmune serum. Immunoprecipitation was carried out on a rotator at room temperature for $90 \mathrm{~min}$. The protein-A-antibody-DNA complexes were washed and DNA was extracted as described by Braunstein et al. (1993). ChIPDNA was analysed by quantitative real-time PCR using primer pairs (Supplementary Table S1) flanking the $\operatorname{arc} A B C$, sly and $g l g C$ promoter regions. The amount of immunoprecipitated DNA was assayed by real-time PCR using a Stratagene (Mx3005P) instrument. The reaction mixture contained $1 \mu \mathrm{l} \mathrm{ChIP}$ or input DNA, $400 \mathrm{nM}$ primers and $10 \mu \mathrm{l}$ SYBR Green Mix (Qiagen) in a total volume of $20 \mu \mathrm{l}$. The
PCR conditions were $95{ }^{\circ} \mathrm{C}$ for $10 \mathrm{~min}, 95{ }^{\circ} \mathrm{C}$ for $20 \mathrm{~s}, 55{ }^{\circ} \mathrm{C}$ for $30 \mathrm{~s}$ and $72{ }^{\circ} \mathrm{C}$ for $20 \mathrm{~s}$, followed by a melting curve of the product as control. Serial dilutions of input DNA revealed linearity from 250 to $8 \mathrm{pg}$, and were used to calculate absolute amounts of PCR products (Hoffmann et al., 2008). Significance $(P<0.01)$ was calculated in a two-sample $t$ test by comparison of DNA obtained after immunoprecipitation with the $\alpha$-rArgR antiserum or preimmune serum.

DNA microarray analysis. For RNA extraction, the wild-type strain and its mutant strain $10 \Delta \mathrm{argR}$ were grown in THB to $\mathrm{OD}_{600} 0.3$ or 0.9 . The cultures were immediately cooled on ice and the bacteria were harvested by centrifugation. Bacteria were resuspended in $1 \mathrm{ml}$ TRIzol reagent (Invitrogen), disrupted by FastPrep three times for $45 \mathrm{~s}$ at intensity setting 6.5, and cooled on ice. After chloroform extraction and 2-propanol precipitation, the RNA was further purified using the RNeasy Mini kit (Qiagen) according to the manufacturer's recommendations. RNA concentration was determined spectrophotometrically, and quality and integrity were confirmed by agarose gel electrophoresis (2100 Bioanalyser, Agilent Technologies). For cDNA synthesis and labelling, a total of $10 \mu \mathrm{g}$ RNA from three independent replicate biological preparations was pooled. Ten micrograms of pooled RNA was reverse-transcribed and labelled with the CyScribe Post-Labelling kit (GE Healthcare, RPN5660) and then purified with the GFX purification kit (GE Healthcare) according to the manufacturer's instructions. Complementary DNA from wild-type strain 10 and mutant strain $10 \Delta \arg R$ was labelled with Cy3 or Cy5, respectively, and analysed in dye-swap microarray experiments to avoid dye-related effects. Equivalent amounts $(25 \mathrm{pmol})$ of $\mathrm{Cy} 3 / \mathrm{Cy} 5$-labelled cDNA were mixed together in hybridization buffer of the in situ Hybridization Kit Plus (Agilent Technologies) following the instructions of the manufacturer. Hybridization was performed at $60{ }^{\circ} \mathrm{C}$ for $17 \mathrm{~h}$. Slides were washed for $10 \mathrm{~min}$ in $6 \times \mathrm{SSC} / 0.05 \%$ Triton $\mathrm{X}-102$ at room temperature, followed by $5 \mathrm{~min}$ in $0.1 \times \mathrm{SSC} / 0.05 \%$ Triton X-102 at $4{ }^{\circ} \mathrm{C}$. Slides were dried using compressed air and scanned in a GenePix 4200AL microarray scanner (Molecular Devices). Scans were analysed using GenePix software (Molecular Devices). A customized in-housedeveloped $R$-based normalization procedure was performed to fit the data. Subsequently, data were analysed using significance analysis of microarrays (SAM). After statistical normalization and evaluation of the dye-swap experiments, genes with more than a twofold ratio change and a $P$ value $<0.05$ were regarded as regulated genes.

The microarray slides used for this study were produced by Agilent Technologies, according to a custom probe design based on the genome sequence of $S$. suis serotype 2 strain P1/7. A total of 7651 unique 60-mers having a theoretical melting temperature of approximately $81{ }^{\circ} \mathrm{C}$ and representing 1960 ORFs were selected as described by Saulnier et al. (2007). Genes were represented at 91, 4, 2 and $3 \%$ by four, three, two oligonucleotides and one oligonucleotide, respectively. A total of 25 putative genes were not represented on the array because no unique 60 -mer satisfying the selection criteria could be selected. Most of the putative genes not represented on the array were relatively short and encoded hypothetical proteins, transposase fragments, prophage proteins, ribosomal proteins and tRNAs.

Real-time quantitative RT-PCR (qRT-PCR). Wild-type strain 10 and its mutant strain $10 \Delta \operatorname{argR}$ were grown in THB medium to early stationary phase and RNA was prepared as described above. Two micrograms of RNA were reverse-transcribed (primers listed in Supplementary Table S1) and analysed by real-time qRT-PCR with a Stratagene Mx3005P system. qRT-PCR settings and conditions were used as described for the ChIP PCR. Data were normalized to a nonregulated housekeeping gene $(\mathrm{dnaH})$ and the relative transcript levels were calculated by the $\Delta \Delta C_{\mathrm{t}}$ method. A two-sample $t$ test was used to calculate the significance $(P<0.05)$ or differential gene expression in strain $10 \Delta \operatorname{argR}$ compared with the wild-type strain. 
Preparation of whole-cell lysates and Western blot analysis. Bacteria were grown in THB to the mid-exponential and early stationary growth phases, and lysates were prepared as described above. Protein concentrations were determined using the Bio-Rad $D_{c}$ protein assay. Proteins were separated by SDS-PAGE and electroblotted onto a PVDF membrane (Serva). Parallel gels were silverstained to control protein loading. Membranes were blocked for $1 \mathrm{~h}$ with $5 \%$ skimmed milk, and then incubated for $2 \mathrm{~h}$ with polyclonal antisera raised against recombinant ArcB (Gruening et al., 2006) or ArgR diluted $1: 100$ or $1: 1000$, respectively, in $0.1 \%$ skimmed milk. Membranes probed with anti-ArcB were developed with conjugated anti-rabbit immunoglobulin $\mathrm{G}$ (Amersham) and chemiluminescence.

Determination of ammonia in the culture supernatant. Ammonia production of the wild-type and the respective mutant strains was monitored with an Ammonia Assay kit (Sigma). For this, bacteria were grown in TY medium and harvested by centrifugation $24 \mathrm{~h}$ after inoculation. The amount of ammonia in the supernatant was determined according to the manufacturer's instructions. To calculate ammonia production $\left(\mathrm{mg} \mathrm{ml}^{-1}\right)$, the ammonia content of TY medium was substracted from the value for the $24 \mathrm{~h}$ culture supernatants.

Survival in cells. The ability of the wild-type strain 10 and the different mutant strains to survive in HEp-2 cells was determined as described previously (Benga et al., 2004), with the modification that, in addition to untreated HEp-2 cells, parallel assays were done with HEp-2 cells that had been pre-treated with bafilomycin (200 nM) for $1 \mathrm{~h}$ to inhibit endosomal acidification. The c.f.u. value was determined and expressed as percentage invasion of the respective inoculum used for infection.

Statistical analysis. If not stated otherwise, statistical analysis was performed by ANOVA followed by a post $t$ test. A $P$ value of $<0.05$ was considered significant.

\section{RESULTS}

\section{Arg $R$ is essential for arcABC operon expression in S. suis}

We have previously characterized the ADS of S. suis as a gene cluster that is bounded at its $5^{\prime}$ and $3^{\prime}$ ends by the genes $f l p S$ and $\operatorname{argR}$, respectively, which are putative regulators of the $\operatorname{arcABC}$ operon (Gruening et al., 2006). In Streptococcus gordonii, the ADS is under the control of ArcR, a member of the arginine repressor family of transcriptional regulators that is homologous to $\arg R$. This prompted us to elucidate the role of $\operatorname{ArgR}$ in $\operatorname{arc} A B C$ operon regulation in S. suis. For this, $\arg R$ was deleted by insertion mutagenesis. The integrity of the mutant strain $10 \Delta \operatorname{argR}$ was controlled by immunoblot analysis of bacterial lysates with a polyclonal antiserum raised against recombinant ArgR (Fig. 1a). To analyse the relevance of ArgR to $\operatorname{arc} A B C$ operon expression, we determined $A r c B$ expression in strain $10 \Delta \operatorname{argR}$ and compared it with that of the wild-type strain 10 and strain $10 \triangle \operatorname{arc} A B C$, which is deficient in $\operatorname{arc} A B C$ operon expression. As shown by immunoblot analysis (Fig. 1b), in the mid-exponential growth phase, ArcB expression was not detectable in either the wild-type strain 10 or the ArgR mutant strain. In early stationary growth, $\mathrm{ArcB}$ expression was enhanced in the wild-type strain 10 alone, while it was not induced in strain
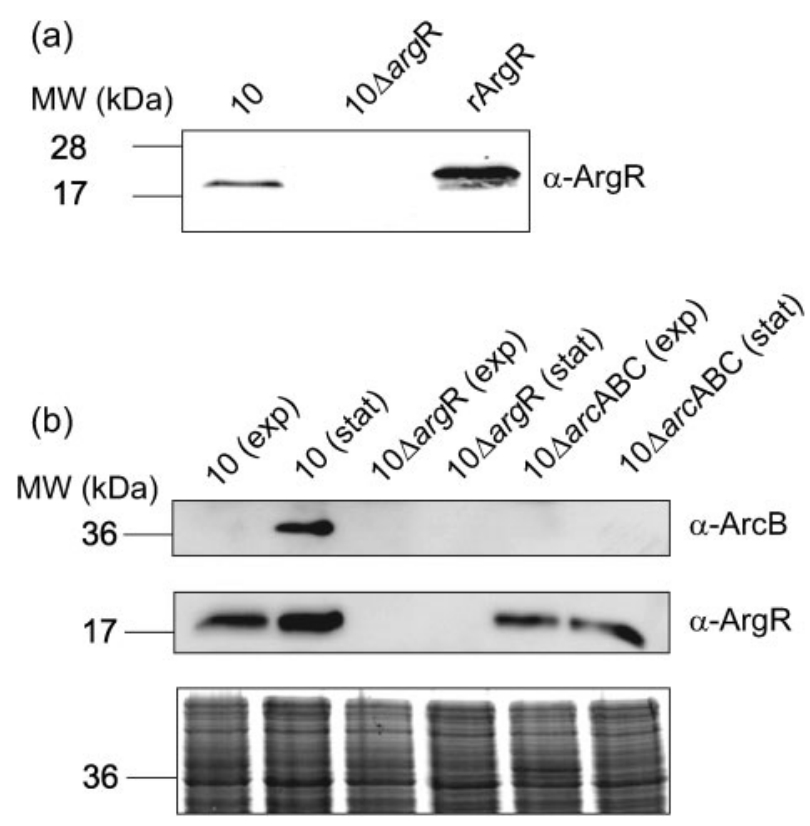

Fig. 1. ArgR is essential for ADS expression. (a) Immunoblot analyses of whole-cell lysates of $S$. suis wild-type strain 10 and strain $10 \Delta \arg \mathrm{R}$ grown to early stationary phase in THB medium. As a control, recombinant ArgR ( $\mathrm{rArgR}$ ) was run in the same gel. Membranes were analysed with a polyclonal antiserum raised against rArgR. (b) Immunoblot analysis of whole-cell lysates obtained from wild-type strain 10, and strains 10 $\Delta \mathrm{arg} \mathrm{R}$ and $10 \triangle$ arcABC probed with polyclonal antisera against recombinant ArcB (top) and ArgR (centre). Bottom, silver-stained gel as a loading control. MW, molecular weight.

$10 \Delta \operatorname{argR}$ and was completely abolished in strain $10 \triangle \operatorname{arcABC}$. These results indicate that ArgR is essential for ArcABC expression of S. suis.

\section{ArgR is important for growth and survival of S. suis}

Further, we compared growth kinetics of the mutant strain $10 \triangle \operatorname{argR}$ with those of the wild-type strain and strain $10 \triangle \operatorname{arcABC}$ in TY medium supplemented with galactose. As shown in Fig. 2(a), starting at $4 \mathrm{~h}$ of culture, both mutant strains were significantly reduced in their growth rate when compared with the wild-type strain. Furthermore, the growth of strain $10 \Delta \operatorname{argR}$ exceeded that of strain $10 \triangle \operatorname{arc} \mathrm{ABC}$, and this was most clearly seen at 6,8 and $24 \mathrm{~h}$. These data indicated that $\arg R$ and the $\operatorname{arc} A B C$ operon are necessary for optimal growth of $S$. suis. Next we monitored $\mathrm{pH}$ and ammonia production during growth of wild-type strain 10 , strain $10 \Delta \operatorname{argR}$ and strain $10 \triangle \operatorname{arc} \mathrm{ABC}$. As shown in Fig. 2(b), both mutant strains were unable to neutralize growth-dependent acidification. Thus, after $24 \mathrm{~h}$ of growth, we could determine a $\mathrm{pH}$ value of about 7.9 in the supernatant of the wild-type strain 10 , whereas $\mathrm{pH}$ values of about 5.6 were detected for strains $10 \Delta \mathrm{argR}$ and $10 \triangle \operatorname{arc} \mathrm{ABC}$, respectively. The differences in neutralizing 
(a)

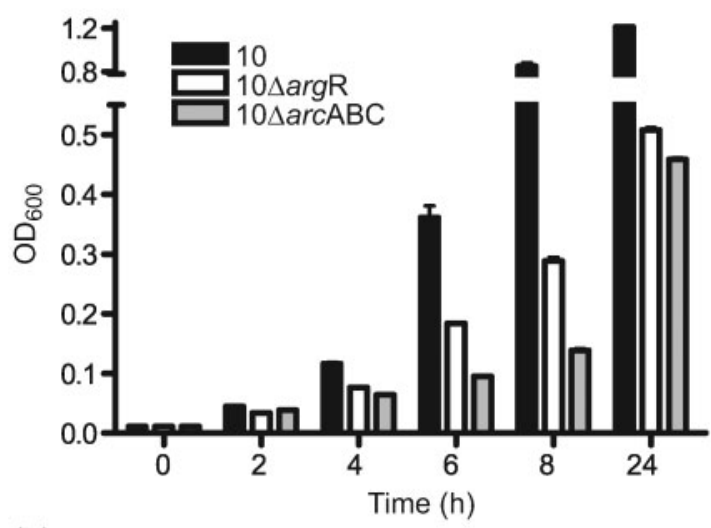

(b)

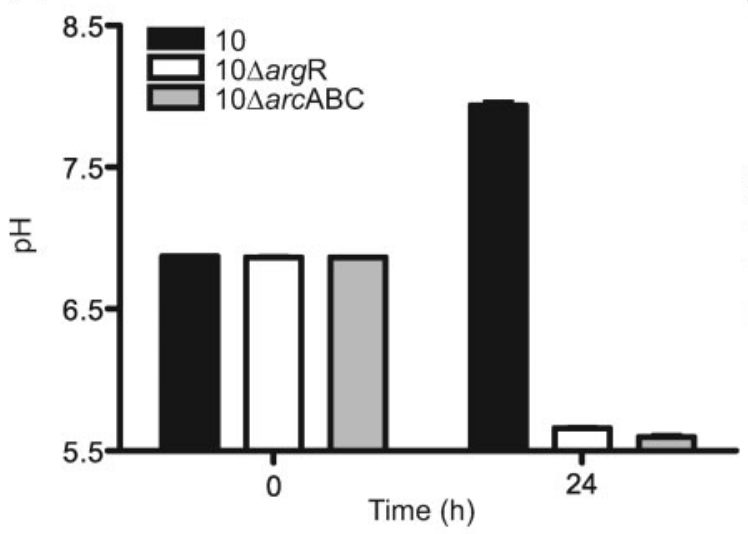

(c)

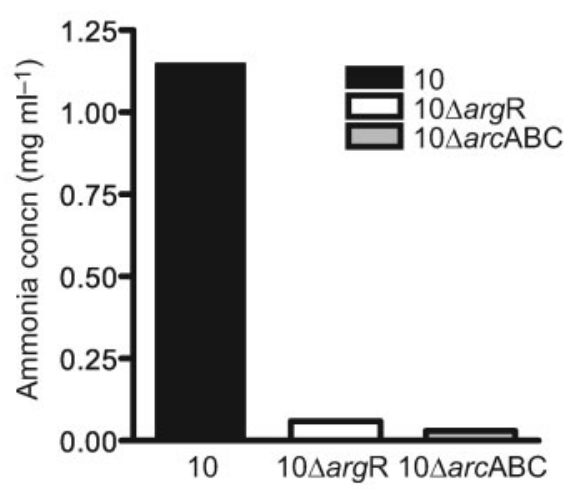

(d)

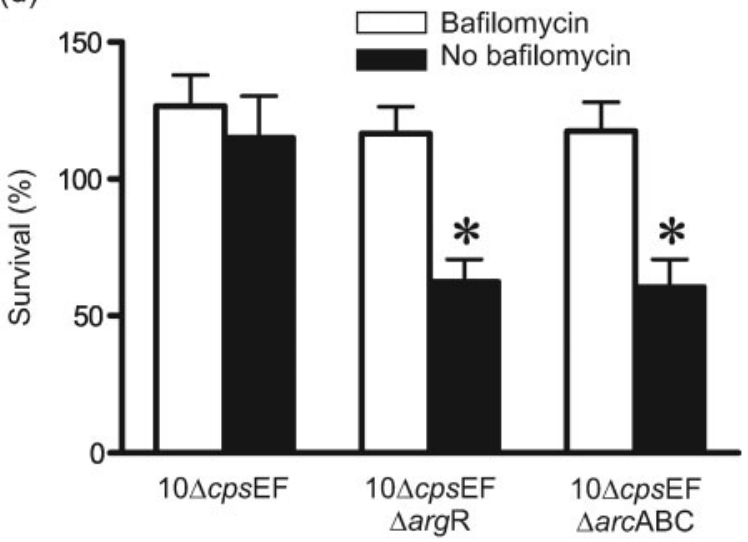

Fig. 2. Influence of ArgR deficiency on the biological fitness of S. suis. (a) S. suis wild-type strain 10, strain $10 \Delta$ argR and strain $10 \triangle$ arcABC were cultured in tryptone-based (TY) minimal medium supplemented with $10 \mathrm{mM}$ galactose. The graph shows bacterial growth, including means and SDS, of the $\mathrm{OD}_{600}$ from a representative experiment performed in triplicate. (b) Bacteria were grown as described in (a). The graph represents the $\mathrm{pH}$ value of the growth medium with means and SDS from a representative experiment performed in triplicate. (c) Wild-type strain 10, strain 10 $\Delta$ argR and strain 10 $\Delta$ arcABC were cultured as described in (a). Ammonia production is given as $\mathrm{mg}$ ammonia ( $\mathrm{ml}$ medium) ${ }^{-1}$. (d) Intracellular survival of the capsuledeficient strains $10 \Delta c p s E F, 10 \Delta c p s E F \Delta a r g R$ and $10 \Delta c p s E F \Delta a r c A B C$ in HEp-2 cells that were treated with bafilomycin $(200 \mathrm{nM})$ for $1 \mathrm{~h}$ before infection (white bars) and in untreated cells (black bars). Results are given as percentage survival in comparison with the initial inoculum. Data represent means and SDs of three independent experiments. Results were considered statistically significant with $P<0.05$, as indicated by asterisks.

growth-dependent acidification after $24 \mathrm{~h}$ corresponded to a loss in ammonia production (Fig. 2c). In contrast to wild-type strain $10\left(1.15 \mathrm{mg} \mathrm{ml}^{-1}\right)$, the ammonia production of strains $10 \Delta \operatorname{arcABC}\left(0.03 \mathrm{mg} \mathrm{ml}^{-1}\right)$ and $10 \Delta \operatorname{argR}$ $\left(0.06 \mathrm{mg} \mathrm{ml}^{-1}\right)$ was markedly reduced. Finally, the survival of ArgR-deficient S. suis in eukaryotic cells was investigated using the human epithelial cell line HEp-2. Since the polysaccharide capsule prevents $S$. suis uptake by epithelial cells, we generated $\operatorname{argR}$ - and $\operatorname{arc} A B C$-deficient strains in a non-encapsulated background (strain $10 \Delta c p s \mathrm{EF}$ ). As shown in Fig. 2(d), strain $10 \Delta c p s E F$ was able to survive and multiply intracellularly at a rate that was about $125 \%$ of the initial inoculum. In contrast, significantly lower survival rates $(60 \%)$ were determined for both doubleknockout mutant strains. To analyse whether reduced survival correlated with the inability of strains
$10 \Delta c p s \mathrm{EF} \Delta \operatorname{argR}$ and $10 \Delta c p s \mathrm{EF} \Delta \operatorname{arc} \mathrm{ABC}$ to generate ammonia and prevent acidification, cells were treated with bafilomycin to inhibit endosomal acidification before infection. Compared with the infection of untreated cells, the pretreatment of the cells with bafilomycin significantly increased the survival rates of strains $10 \Delta c p s \mathrm{EF} \Delta \arg \mathrm{R}$ and $10 \Delta c p s \mathrm{EF} \Delta \operatorname{arc\mathrm {ABC}}$. These data suggest that $S$. suis is able to resist endosomal acidification by ArgR-dependent $\operatorname{arc} A B C$ operon induction and ammonia production.

\section{ArgR deficiency specifically affects arcABC operon expression}

The above results indicated that ArgR is an important regulator of the $\operatorname{arc} A B C$ operon in S. suis. The differences in the growth kinetics of strains $10 \Delta \operatorname{argR}$ and $10 \Delta \operatorname{arc} \mathrm{ABC}$, 
however, suggested that ArgR might have additional regulatory functions. To test this, we performed wholegenome cDNA microarray analyses to evaluate the relevance of ArgR to S. suis gene expression. RNA was extracted from strain $10 \Delta \operatorname{argR}$ and wild-type strain 10 grown to the midexponential (reflecting a similar growth of $10 \Delta \mathrm{argR}$ and $10 \triangle \operatorname{arc} \mathrm{ABC}$ ) and early stationary phases, when the growth of $10 \Delta \operatorname{argR}$ clearly differed from that of $10 \Delta \operatorname{arcABC}$ (Fig. 2a). After reverse transcription, cDNA of strain $10 \Delta \operatorname{argR}$ and the wild-type strain 10 was analysed on a whole-genome $S$. suis strain P1/7 microarray. A comparison of the microarray data of the bacteria grown to the mid-exponential growth phase revealed no genes significantly up- or downregulated by ArgR (Supplementary Table S2). In the early stationary growth phase, 26 genes were differentially expressed (with $P$ values of $<0.05$ ) between the wild-type and the mutant strain (Table 1). Interestingly, expression of only five genes was significantly reduced in the mutant strain. As expected, one of them was $\operatorname{argR}$, for which mRNA expression was abolished (downregulation 124-fold). The other four genes with strongly reduced mRNA expression in the mutant strain (downregulation of $\leqslant 28$-fold, Table 1 ) represented the members of the $\operatorname{arcABC}$ operon, $\operatorname{arcA}$, SSU0581, $\operatorname{arcB}$ and $\operatorname{arc} C$. In addition, only mRNA expression of a putative trehalose-6-phosphate hydrolase (treA) was negatively influenced by ArgR deficiency (-3.7-fold). The 20 genes with higher mRNA expression in the mutant strain comprised seven ribosomal proteins (rplM, rplT, rpmI, $r p s D, \quad r p s L, r p s P$ and $r p s U$ ), six hypothetical proteins (SSU0068, SSU297, SSU0810, SSU1181, SSU1391 and SSU1936), two hydrolase family proteins (SSU1578 and SSU1763), the adenylate kinase ( $a d k)$, an exoDNase (exoA), the translation initiation factor IF-3 (infC), a mechanosensitive channel protein $(m s c L)$ and suilysin $(s l y)$. Their lower level of expression differences, which was at maximum less than 7.3-fold, compared with the genes of the $\operatorname{arc} A B C$ operon, suggests that these genes and treA might be influenced indirectly by the ArgR deficiency. qRT-PCR analyses were performed to confirm the array data. Expression levels of $\operatorname{arcB}$, which is representative of the $\operatorname{arc} A B C$ operon, $\operatorname{argR}, s l y$, treA, adk and $g l g C$ were determined. Interestingly, significant differences in the gene expression of stationary-grown strains 10 and $10 \Delta \operatorname{argR}$ could be confirmed only for $\operatorname{arcB}$ and $\arg R$. In contrast, the expression levels of $s l y$, treA and adk did not differ significantly from that of $g l g C$, which was included as a control gene with similar expression in strains 10 and $10 \Delta \operatorname{argR}$.

Another interesting finding was that ArgR deficiency did not alter mRNA expression of the arginine anabolic genes argininosuccinate synthase $(\arg G)$ and argininosuccinate lyase $(\operatorname{argH})$, which have been reported to be regulated by ArgR in other Gram-positive bacteria (Larsen et al., 2004, 2005, 2008; Ryan et al., 2009) (Table 1). This was confirmed by qRT-PCR analysis (Fig. 3). In conclusion, the results of microarray and qRT-PCR analyses strongly suggest that in $S$. suis, $\operatorname{ArgR}$ is a specific, positive transcriptional regulator of the $\operatorname{arc} A B C$ operon.

\section{ArgR binds to and activates the $\operatorname{arcABC}$ operon promoter}

To further analyse the regulatory function of $\operatorname{ArgR}$ in $\operatorname{arc} A B C$ operon expression, we cloned a 788 bp fragment representing the promoter-operator region of the $\operatorname{arc} A B C$ operon into the $g f p$ reporter vector $p \mathrm{GA} 14_{\mathrm{spc}}-g f p$ and transformed it into S. suis strains 10 and $10 \Delta \operatorname{argR}$. As a control, wild-type strain 10 was transformed with the promoterless $p \mathrm{GA} 14_{\mathrm{spc}^{-}} g f p$ vector. Bacteria were grown in galactose-containing TY medium to the stationary growth phase, and reporter gene activity was then determined by fluorescence measurement. As shown in Fig. 4(a), compared with the control, the wild-type strain was able to induce reporter gene activity. In contrast, nearly no $g f p$ expression could be detected in strain $10 \Delta \operatorname{argR}$, showing that $\arg R$ is essential for reporter gene activity. In conclusion, $\operatorname{ArgR}$ was shown to interact with the $\operatorname{arc} A B C$ operon promoter.

We have previously shown that the $\operatorname{arc} A B C$ operon promoter region contains a putative far-upstream ArgRbinding site (Gruening et al., 2006). Therefore, we transformed wild-type strain 10 with the $g f p$ reporter vector $p \mathrm{GA} 14_{\mathrm{spc}}-g f p$, in which the putative ArgR-binding site was deleted by excision of $522 \mathrm{bp}$ of the $5^{\prime} \operatorname{arc} A B C$ operon promoter-operator region. As shown in Fig. 4(b), similar to the full-length promoter, reporter gene expression was still present after deletion of the putative ArgRbinding site, indicating that ArgR binding occurred further downstream. In silico analysis of the $5^{\prime}$-truncated $\operatorname{arc} A B C$ operon promoter-operator region using the virtual footprint promoter analysis program (Münch et al., 2005) revealed three AT-rich elements (ARG-boxes) with homologies to the predicted ArgR-binding site in E. coli (Fig. 4c). According to the positions of the ARG-boxes, we generated four PCR fragments of different lengths (Fig. 4c), which were investigated for ArgR DNA binding by EMSA. The DNA fragments were incubated with recombinant ArgR, and DNA binding to the PCR fragments was assayed after native gel electrophoresis and ethidium bromide staining. As shown in Fig. 4(d), recombinant ArgR was able to bind to fragments 3 and 4 containing ARG-boxes 2 and 3 (indicated by the retarded mobility of DNA fragments after incubation with $\operatorname{ArgR}$ ), whereas the shorter fragments 1 and 2 containing ARG-box 1 were unable to bind ArgR.

Interestingly, the ArgR-binding region was located within the predicted operator region of the $\operatorname{arc} A B C$ operon, which is contradictory to its role as a positive regulator. This prompted us to redefine the transcriptional start point and to revise the $\operatorname{arc} A B C$ promoter structure. Repeated $5^{\prime}$ RACE analyses identified a tyrosine 79 bp upstream of the ArcA ATG as the transcriptional start (data not shown and Fig. 4c).

These data revealed that, based on the corrected transcriptional start point, a region between -147 and $-72 \mathrm{bp}$ within the $\operatorname{arc} A B C$ promoter sequence (-147-72-box) seems to be necessary for ArgR binding in vitro. 
Table 1. Comparative microarray analysis of $S$. suis wild-type strain 10 and strain $10 \Delta$ argR grown to early stationary phase $\left(\mathrm{OD}_{600} 0.9\right)$

Significantly regulated genes are shown for a lowest false-discovery rate of $P<0.05$. NS, Not significant.

\begin{tabular}{|c|c|c|c|}
\hline $\begin{array}{l}\text { ORF in } \\
\text { strain } P 1 / 7\end{array}$ & Gene & Gene product & $\begin{array}{l}\text { Fold change gene } \\
\text { expression }\end{array}$ \\
\hline SSU0068 & $\operatorname{com} X 2$ & Putative competence-specific global transcription modulator (fragment) & +3.11 \\
\hline SSU0094 & $a d k$ & Adenylate kinase & +3.08 \\
\hline SSU0148 & rpsL & $30 \mathrm{~S}$ ribosomal protein $\mathrm{S} 12$ & +2.84 \\
\hline SSU0216 & treA, treC & Putative trehalose-6-phosphate hydrolase & -3.68 \\
\hline SSU0297 & & Putative transcription regulation protein & +3.61 \\
\hline SSU0580 & $\operatorname{arcA}$ & Arginine deiminase & -28.15 \\
\hline SSU0581 & & Acetyltransferase (GNAT) family protein & -36.66 \\
\hline SSU0582 & $\operatorname{arcB}$ & Ornithine carbamoyltransferase & -29.96 \\
\hline SSU0583 & $\operatorname{arcC}$ & Carbamate kinase & -28.49 \\
\hline SSU0588 & $\arg R$ & Arginine repressor & -124.67 \\
\hline SSU0627 & exoA & ExoDNase & +3.63 \\
\hline SSU0742 & $r p s P$ & $30 \mathrm{~S}$ ribosomal protein $\mathrm{S} 16$ & +3.16 \\
\hline SSU0810 & & Conserved hypothetical protein & +6.18 \\
\hline SSU0870 & $\operatorname{glg} C$ & ADP-glucose pyrophosphorylase & NS \\
\hline SSU1104 & $\operatorname{rplT}$ & 50 S ribosomal protein L20 & +2.88 \\
\hline SSU1105 & rpmI & 50 S ribosomal protein L35 & +3.29 \\
\hline SSU1106 & infC & Translation initiation factor IF-3 & +3.03 \\
\hline SSU1181 & & Putative membrane protein & +3.01 \\
\hline SSU1231 & sly & Suilysin (haemolysin) & +3.23 \\
\hline SSU1257 & $m s c L$ & Large-conductance mechanosensitive channel & +4.34 \\
\hline SSU1259 & $r p s U$ & 30 S ribosomal protein $\mathrm{S} 21$ & +4.01 \\
\hline SSU1391 & & Putative membrane protein & +3.98 \\
\hline SSU1463 & $\arg R$ & Putative arginine repressor & NS \\
\hline SSU1578 & & Gamma-glutamyl hydrolase & +4.22 \\
\hline SSU1692 & rplM & 50 S ribosomal protein $\mathrm{L} 13$ & +2.77 \\
\hline SSU1763 & & MutT/NUDIX hydrolase family protein & +2.92 \\
\hline SSU1806 & $\arg G$ & Argininosuccinate synthase (citrulline-asparate ligase) & NS \\
\hline SSU1807 & $\operatorname{argH}$ & Argininosuccinate lyase & NS \\
\hline SSU1909 & $\arg R$ & Putative arginine repressor & NS \\
\hline SSU1935 & $r p s D$ & 30 S ribosomal protein $\mathrm{S} 4$ & +3.51 \\
\hline SSU1936 & & Hypothetical protein & +7.84 \\
\hline
\end{tabular}

${ }^{\star}$ Fold change gene expression is given as a positive $(+)$ or negative $(-)$ value representing upregulation or downregulation in strain $10 \Delta a r g \mathrm{R}$, respectively.

\section{ArgR interacts with the arcABC operon promoter in vivo}

The above results indicated the relevance of ArgR and the ArgR-binding sites within the $\operatorname{arc} A B C$ promoter to $\operatorname{arc} A B C$ operon expression. Next we analysed whether ArgR physically interacts with the $-147-72$-box of the $\operatorname{arc} A B C$ promoter in vivo by chromatin immunoprecipitation analyses. For this, wild-type strain 10 and strain $10 \Delta \operatorname{argR}$ grown either to mid-exponential or to early stationary phase were analysed by ChIP assays with preimmune or $\alpha$ ArgR antiserum. After DNA extraction, binding of ArgR to the -147-72-box was determined by real-time qRT-PCR with the oligonucleotide primer pair ChIP-for/ChIP-rev indicated in Fig. 4(c) and calculating the amounts of amplified fragments. As controls, we investigated ArgR binding to the promoter region of the ADP-glucose pyrophosphorylase gene $(g \lg C)$ and the suilysin gene $(s l y)$. According to the results of our real-time qRT-PCR studies, these genes were not regulated by ArgR (Fig. 3), and thus the promoters should not be recruited by ArgR. As depicted in Fig. 5, $0.2 \mathrm{ng}$ of $\operatorname{arcABC}$ promoter DNA was precipitated in the mid-exponential phase with antibodies directed against ArgR, using wild-type strain 10. Growth to stationary phase enhanced the yield of DNA to $0.35 \mathrm{ng}$, which indicated in vivo binding of ArgR to the $\operatorname{arc} A B C$ promoter. In contrast, only low amounts of DNA were detected in experiments using the preimmune serum or in experiments using strain $10 \Delta \operatorname{argR}$, indicating a high specificity of the $\alpha$-ArgR antiserum. As expected, the ChIP experiments revealed that $\mathrm{ArgR}$ did not bind to the sly and $g \lg C$ promoters. These analyses demonstrate that $\mathrm{ArgR}$ binds to the $\operatorname{arc} A B C$ promoter in vivo. 


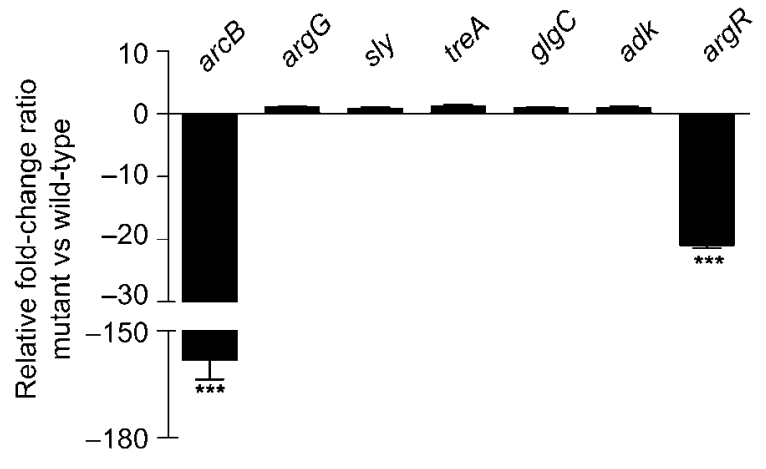

Fig. 3. ArgR mutation specifically affects $\operatorname{arc} A B C$ operon expression. $S$. suis wild-type strain 10 and the $\operatorname{argR\text {-deficient}}$ mutant strain $10 \Delta a r g R$ were grown in THB medium to early stationary phase. Transcript levels of the indicated genes were determined by real-time qRT-PCR. Signals were normalized to a housekeeping gene $(d n a H)$ and relative gene expression was calculated by the $\Delta \Delta C_{t}$ method. The relative fold-change ratio indicates the ratio of the values obtained for strain $10 \Delta \mathrm{argR}$ and the wild-type. Data are shown with mean and SD for three independent real-time qRT-PCR analyses performed in duplicate. A significant difference $(P<0.05)$ was defined as at least a twofold change in gene expression compared with wild-type strain 10 . $\operatorname{arcB}$, ornithine carbamoyltransferase; $\arg G$, argininosuccinate synthase; sly, suilysin; tre $A$, putative trehalose-6-phosphate hydrolase; $g l g C$, ADP-glucose pyrophosphorylase; adk, adenylate kinase; argR, arginine repressor (SSU0588).

\section{DISCUSSION}

This study showed that ArgR is essential for $\operatorname{arc} A B C$ operon expression of the ADS gene cluster in S. suis. Furthermore, we could demonstrate that, in contrast to other bacteria, $\operatorname{ArgR}$ is a local regulator that specifically interacts with the $\operatorname{arc} A B C$ operon promoter in S. suis. In our previous work we found that in S. suis, the genes of the $\mathrm{ADS}$ are located on a gene cluster consisting of the $\operatorname{arc} A B C$ operon, the genes for a putative arginine/ornithine antiporter $(\operatorname{arcD})$, a putative Xaa-His dipeptidase $(\operatorname{arcT})$, a putative endo- $\beta$-galactosidase $(\operatorname{arcH})$, and the genes of two regulatory factors, FlpS and ArgR, at the $5^{\prime}$ and $3^{\prime}$ ends, respectively (Gruening et al., 2006).

The members of the ArgR/AhrC family of transcriptional regulators are mediators of arginine metabolism regulation. ArgR proteins and their cognate target sites are highly conserved among very diverse organisms, including Grampositive and Gram-negative bacteria. In general, ArgR proteins regulate their target genes by binding to operator sites, leading to repression of arginine biosynthetic genes and activation of catabolic genes (Gardan et al., 1995; Grandori et al., 1995; Kiupakis \& Reitzer, 2002; Klingel et al., 1995; Lu \& Abdelal, 1999; Makarova et al., 2001).

Here we used the isogenic $\operatorname{argR}$-negative mutant strain $10 \triangle \arg \mathrm{R}$ and immunoblot analysis to demonstrate that $A r g R$ is a positive regulator of arcABC expression in S. suis which is essential for induction of $\operatorname{arc} A B C$ expression. This result is in agreement with findings that $\operatorname{ArgR}$ proteins are activators of arginine catabolic genes, as has been described for other Gram-positive bacteria such as Bacillus licheniformis and S. gordonii (Maghnouj et al., 1998; Zeng et al., 2006). However, the array and qRT-PCR analyses revealed that ArgR seems solely to regulate the $\operatorname{arc} A B C$ operon. This was indicated by the significantly reduced mRNA expression of the $\operatorname{arc} A B C$ genes in strain $10 \triangle \operatorname{argR}$ in the early stationary growth phase in both assays. Regulation of a single system by ArgR has not yet been described and is different to that in many other bacteria, in which ArgR has been shown to regulate both arginine anabolic and arginine catabolic genes (Hashim et al., 2004; Hernández-Flores et al., 2004; Larsen et al., 2004, 2005, 2008; Lu et al., 2004; Park et al., 1997). From our array analyses we could exclude any polar effects due to the insertion mutation, since expression of the genes upstream (SSU0587) and downstream (SSU0589) of argR (SSU0588) was not significantly altered (Supplementary Table S2).

The fact that ArgR seems to be a highly specific regulator of the $\operatorname{arc} A B C$ operon in $S$. suis was underlined by several findings. First of all, our array analyses with RNA from mid-exponential growth did not reveal any significantly differentially expressed genes in strain 10 $\operatorname{argR}$. Furthermore, there was no evidence of an ArgR-dependent regulation of the $\operatorname{argGH}$ operon, which seems to be the only arginine anabolic system in S. suis, as no other putative anabolic gene clusters such as $\operatorname{argCJDBF}$ or gltS$\arg E$ can be identified in the $S$. suis genome annotation. Second, in early stationary growth, the array analyses revealed a small number of genes with a low degree of differential expression in strain 10 $\Delta$ argR. The qRT-PCR analyses revealed that the genes were regulated twofold maximally. Notably, most of them are connected to ATP generation, which is plausible, as ATP production by ArcABC is strongly reduced in strain $10 \triangle \operatorname{argR}$. For example, the adenylate kinase (Adk) produces ATP and AMP from two moles of ADP (Willemoës \& Kilstrup, 2005). The trehalose-6-phosphate hydrolase (TreC) catalyses the conversion of trehalose 6-phosphate to glucose and glucose 6-phosphate (Rimmele \& Boos, 1994). Thus, it is very likely that these genes are not primarily regulated by ArgR. Third, our ChIP analysis demonstrated clearly that ArgR binds to the $\operatorname{arc} A B C$ promoter in vivo. Finally, all our phenotypical tests revealed that, in comparison with the wild-type strain 10 , strain $10 \Delta \operatorname{argR}$ was affected in growth and biological fitness to an extent similar to that of strain $10 \triangle \operatorname{arcABC}$ (Fig. 2). These assays also demonstrated that enhanced $\operatorname{arc} A B C$ expression mediated by $\mathrm{ArgR}$ is essential for optimal growth and intracellular survival of S. suis.

Regulation of the ArgR family of transcriptional regulators is exerted by binding to so-called ARG operator sites that precede the relevant target genes. ARG operator sites consist of pairs of $18 \mathrm{bp}$ palindromic sequences (called ARG-boxes), of which the 5'-TnTGnATwwwwATnCAnA$3^{\prime}$ (conserved residues in upper-case type; $\mathrm{n}$, any nucleotide; 
(a)

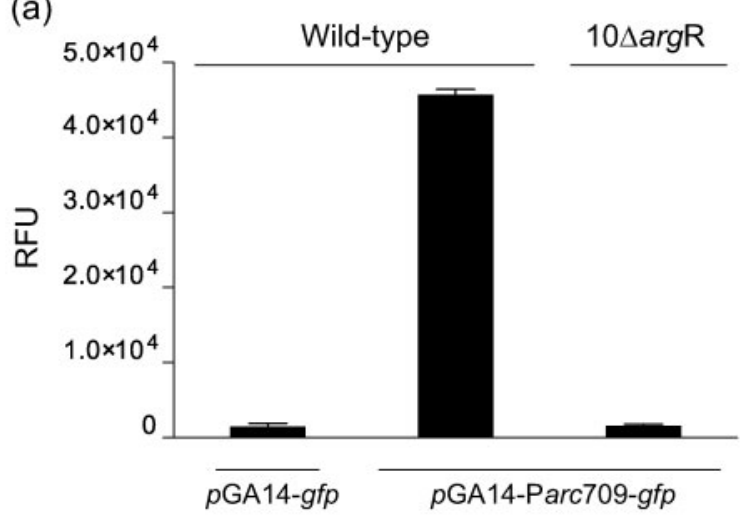

(c)

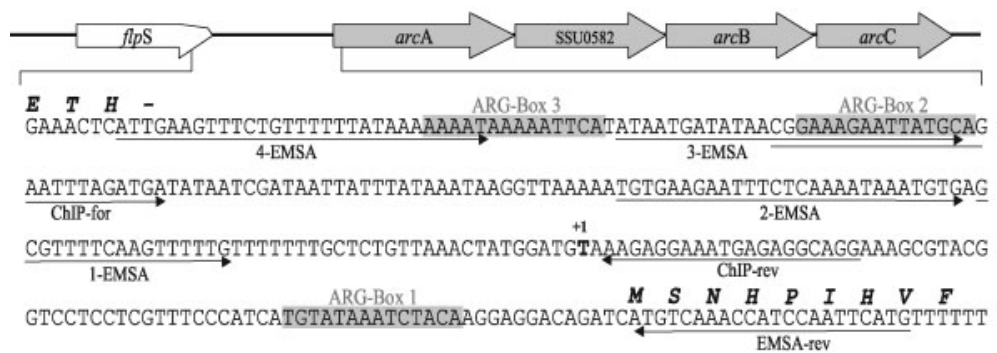

(b)

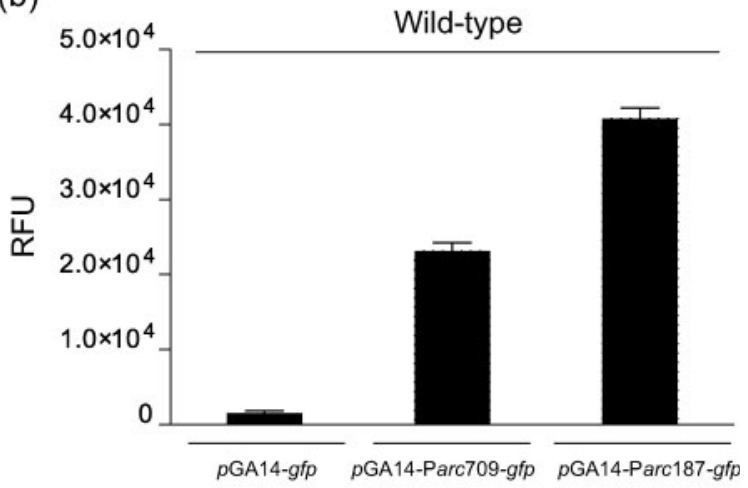

(d)

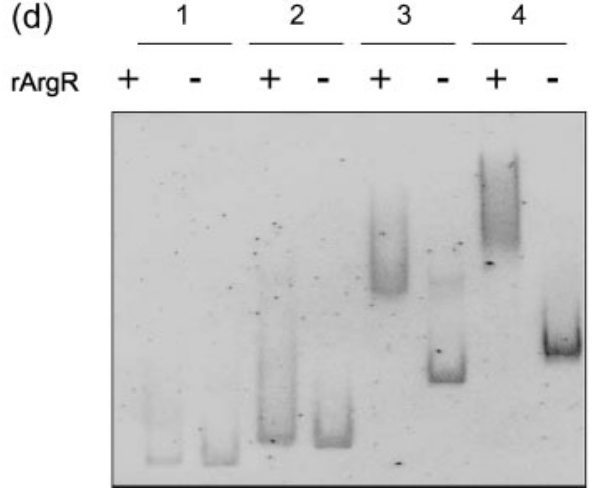

Fig. 4. $\operatorname{ArgR}$ binds to and activates the $\operatorname{arc} A B C$ operon promoter. S. suis wild-type strain 10 , and strain $10 \triangle \arg \mathrm{R}$ harbouring the plasmid $p$ GA14 spc - Parc709-gfp (a) or wild-type strain 10 harbouring either plasmid $p$ GA14 spc $^{-P a r c 709-g f p ~ r e p r e s e n t i n g ~}$ the whole arcABC promoter region (Parc709) or the far upstream ARG-box-deleted version (Parc187) (b), were grown for $8 \mathrm{~h}$ in TY medium. Bars represent the relative fluorescence units (RFU) after subtracting the absolute values for the PBS control. Wild-type strain 10 harbouring the promoterless construct $p \mathrm{GA} 14_{\mathrm{spc}}$-gfp served as negative control. Experiments were carried out in triplicate and repeated at least twice. (c) Schematic representation of the S. suis arcABC operon promoter. The three putative ArgR $14 \mathrm{bp}$ binding sites with highest homology to the E. coli ArgR-binding site are shown in grey. The transcriptional start point determined by $5^{\prime}-$ RACE is indicated $(+1)$; the predicted amino acid sequences of the $3^{\prime}$-primed flpS gene and $5^{\prime}-$ primed $\operatorname{arc} A$ gene are shown in italic type. Primer sequences used for amplification of $\operatorname{arc} A B C$ promoter segments analysed by EMSA and ChIP are indicated by underlining arrows. (d) PCR fragments were generated with the primers 1-EMSA, 2-EMSA, 3EMSA and 4-EMSA (1-4) in combination with EMSA-rev [positions as indicated in (c)] and analysed in an EMSA after a $1 \mathrm{~h}$ incubation with $(+)$ or without $(-)$ recombinant ArgR ( $r A r g R)$. Gel retardation by DNA-protein complexes was monitored after ethidium bromide staining.

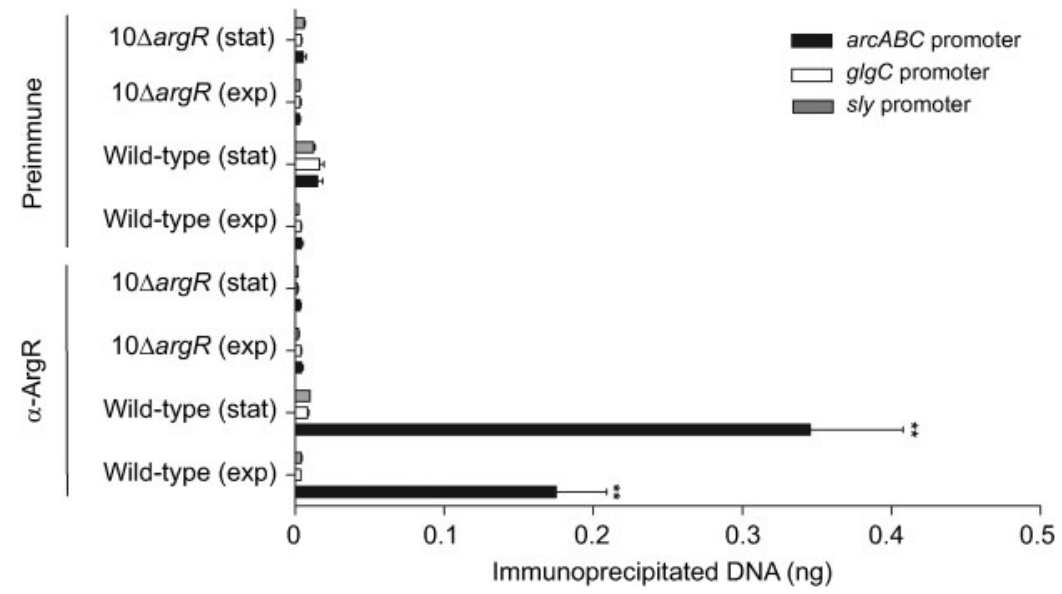

Fig. 5. ArgR binds to the $\operatorname{arc} A B C$ promoter in vivo. For ChIP assays, wild-type strain 10 and strain $10 \Delta \arg \mathrm{R}$ were grown in THB medium to the exponential (exp) and stationary (stat) phases. ChIP lysate chromatin was precipitated using either $\alpha$-ArgR or preimmune serum. ChIP DNA was quantified by real-time qRTPCR using primer pairs for the arc $A B C$ (black bars), sly (grey bars) and $g / g C$ (white bars) promoter regions. The graphs represent means and SDS of immunoprecipitated DNA from three independent experiments. Significance $(P<0.01)$ was calculated in a two-sample $t$ test by comparing wild-type strain 10 and strain 10 $\Delta$ argR. 
w, A or T) consensus sequence in E. coli (Maas, 1994) is conserved with only small variations in various other organisms studied (Cherney et al., 2008; Garnett et al., 2008; Makarova et al., 2001). Our promoter studies with the $\operatorname{arc} A B C$ promoter-operator $-g f p$ constructs indicated that ArgR is responsible for $\operatorname{arc} A B C$ promoter activity. Furthermore, we could exclude the relevance to $\operatorname{arc} A B C$ promoter activity of a putative ARG-box in the $5^{\prime}$ promoter region of the $\operatorname{arc} A B C$ promoter that we identified in a previous study (Gruening et al., 2006). Further in silico analysis of the $\operatorname{arc} A B C$ promoter-operator region with the virtual footprint promoter prediction program (Münch et al., 2005) revealed three further putative ARG-boxes. Gel retardation assays with recombinant $\mathrm{ArgR}$ and truncated fragments of the $\operatorname{arc} A B C$ promoter-operator region allowed us to identify a DNA-binding region of 75 bp that was able to interact with recombinant ArgR. Since the identification of potential A+T-rich ArgR-binding sites in silico and by EMSA does not reflect the in vivo situation (not all binding sites may be predicted in silico or weak binding sites relevant in vivo may not be recognized by EMSA), we performed ChIP analysis, which demonstrated that ArgR physically interacts with the $\operatorname{arc} A B C$ promoter region in vivo. The context of ArgR binding to the ARG-boxes in the promoter sequence, however, awaits further studies.

In conclusion, our data indicate that ArgR is an essential, local transcriptional regulator of $\operatorname{arc} A B C$ operon expression in S. suis. Its specificity for the ADS makes it highly relevant to the biological fitness of $S$. suis.

\section{ACKNOWLEDGEMENTS}

We gratefully acknowledge Sven Hammerschmidt, Ernst Moritz Arndt Universität Greifswald, Germany, for providing plasmid pDL278-gfpmut $3^{\star}$, and Christoph Baums, Stiftung Tierärztliche Hochschule Hannover, Germany, for providing plasmid $p \mathrm{IC}_{\mathrm{erm}}$. This work was supported by the Deutsche Forschungsgemeinschaft (DFG), Bonn, Germany (SFB 578 and GRK 745) and a Georg Christoph Lichtenberg stipend to J.W. (ZIB, Centre for Infection Biology).

\section{REFERENCES}

Arends, J. P. \& Zanen, H. C. (1988). Meningitis caused by Streptococcus suis in humans. Rev Infect Dis 10, 131-137.

Barcelona-Andrés, B., Marina, A. \& Rubio, V. (2002). Gene structure, organization, expression, and potential regulatory mechanisms of arginine catabolism in Enterococcus faecalis. J Bacteriol 184, 62896300

Benga, L., Goethe, R., Rohde, M. \& Valentin-Weigand, P. (2004). Non-encapsulated strains reveal novel insights in invasion and survival of Streptococcus suis in epithelial cells. Cell Microbiol 6, 867-881.

Blakemore, R. P. \& Canale-Parola, E. (1976). Arginine catabolism by Treponema denticola. J Bacteriol 128, 616-622.

Braunstein, M., Rose, A. B., Holmes, S. G., Allis, C. D. \& Broach, J. R. (1993). Transcriptional silencing in yeast is associated with reduced nucleosome acetylation. Genes Dev 7, 592-604.
Broman, K., Lauwers, N., Stalon, V. \& Wiame, J. M. (1978). Oxygen and nitrate in utilization by Bacillus licheniformis of the arginase and arginine deiminase routes of arginine catabolism and other factors affecting their syntheses. J Bacteriol 135, 920-927.

Burne, R. A., Parsons, D. T. \& Marquis, R. E. (1989). Cloning and expression in Escherichia coli of the genes of the arginine deiminase system of Streptococcus sanguis NCTC 10904. Infect Immun 57, 35403548.

Caldara, M., Charlier, D. \& Cunin, R. (2006). The arginine regulon of Escherichia coli: whole-system transcriptome analysis discovers new genes and provides an integrated view of arginine regulation. Microbiology 152, 3343-3354.

Champomier Vergès, M. C., Zuñiga, M., Morel-Deville, F., PerezMartinez, G., Zagorec, M. \& Ehrlich, S. D. (1999). Relationships between arginine degradation, $\mathrm{pH}$ and survival in Lactobacillus sakei. FEMS Microbiol Lett 180, 297-304.

Chanter, N., Jones, P. W. \& Alexander, T. J. (1993). Meningitis in pigs caused by Streptococcus suis - a speculative review. Vet Microbiol 36, 39-55.

Chaussee, M. S., Somerville, G. A., Reitzer, L. \& Musser, J. M. (2003). Rgg coordinates virulence factor synthesis and metabolism in Streptococcus pyogenes. J Bacteriol 185, 6016-6024.

Cherney, L. T., Cherney, M. M., Garen, C. R., Lu, G. J. \& James, M. N. (2008). Crystal structure of the arginine repressor protein in complex with the DNA operator from Mycobacterium tuberculosis. J Mol Biol 384, 1330-1340.

Clifton-Hadley, F. A. \& Alexander, T. J. (1980). The carrier site and carrier rate of Streptococcus suis type II in pigs. Vet Rec 107, 40-41.

Crow, V. L. \& Thomas, T. D. (1982). Arginine metabolism in lactic streptococci. J Bacteriol 150, 1024-1032.

Dong, Y. Q., Chen, Y. Y. M. \& Burne, R. A. (2004). Control of expression of the arginine deiminase operon of Streptococcus gordonii by CcpA and Flp. J Bacteriol 186, 2511-2514.

Floderus, E., Linder, L. E. \& Sund, M. L. (1990). Arginine catabolism by strains of oral streptococci. APMIS 98, 1045-1052.

Gardan, R., Rapoport, G. \& Debarbouille, M. (1995). Expression of the rocDEF operon involved in arginine catabolism in Bacillus subtilis. J Mol Biol 249, 843-856.

Garnett, J. A., Marincs, F., Baumberg, S., Stockley, P. G. \& Phillips, S. E. (2008). Structure and function of the arginine repressoroperator complex from Bacillus subtilis. J Mol Biol 379, 284-298.

Gottschalk, M., Xu, J., Calzas, C. \& Segura, M. (2010). Streptococcus suis: a new emerging or an old neglected zoonotic pathogen? Future Microbiol 5, 371-391.

Grandori, R., Lavoie, T. A., Pflumm, M., Tian, G. L., Niersbach, H., Maas, W. K., Fairman, R. \& Carey, J. (1995). The DNA-binding domain of the hexameric arginine repressor. J Mol Biol 254, 150-162.

Gruening, P., Fulde, M., Valentin-Weigand, P. \& Goethe, R. (2006). Structure, regulation, and putative function of the arginine deiminase system of Streptococcus suis. J Bacteriol 188, 361-369.

Hashim, S., Kwon, D. H., Abdelal, A. \& Lu, C. D. (2004). The arginine regulatory protein mediates repression by arginine of the operons encoding glutamate synthase and anabolic glutamate dehydrogenase in Pseudomonas aeruginosa. J Bacteriol 186, 3848-3854.

Hernández-Flores, J. L., Lopez-Lopez, K., Garciduenas-Pina, R., Jofre-Garfias, A. E. \& Alvarez-Morales, A. (2004). The global arginine regulator ArgR controls expression of argF in Pseudomonas syringae pv. phaseolicola but is not required for the synthesis of phaseolotoxin or for the regulated expression of argK. J Bacteriol 186, 3653-3655.

Hoffmann, E., Ashouri, J., Wolter, S., Doerrie, A., Dittrich-Breiholz, O., Schneider, H., Wagner, E. F., Troppmair, J., Mackman, N. \& other 
authors (2008). Transcriptional regulation of EGR-1 by the interleukin-1-JNK-MKK7-c-Jun pathway. J Biol Chem 283, 12120-12128.

Kiupakis, A. K. \& Reitzer, L. (2002). ArgR-independent induction and ArgR-dependent superinduction of the astCADBE operon in Escherichia coli. J Bacteriol 184, 2940-2950.

Klingel, U., Miller, C. M., North, A. K., Stockley, P. G. \& Baumberg, S. (1995). A binding-site for activation by the Bacillus subtilis AhrC protein, a repressor activator of arginine metabolism. Mol Gen Genet 248, 329-340.

Larsen, R., Buist, G., Kuipers, O. P. \& Kok, J. (2004). ArgR and AhrC are both required for regulation of arginine metabolism in Lactococcus lactis. J Bacteriol 186, 1147-1157.

Larsen, R., Kok, J. \& Kuipers, O. P. (2005). Interaction between ArgR and AhrC controls regulation of arginine metabolism in Lactococcus lactis. J Biol Chem 280, 19319-19330.

Larsen, R., van Hijum, S. A., Martinussen, J., Kuipers, O. P. \& Kok, J. (2008). Transcriptome analysis of the Lactococcus lactis ArgR and AhrC regulons. Appl Environ Microbiol 74, 4768-4771.

Liu, Y., Dong, Y., Chen, Y. Y. \& Burne, R. A. (2008). Environmental and growth phase regulation of the Streptococcus gordonii arginine deiminase genes. Appl Environ Microbiol 74, 5023-5030.

Lu, C. D. \& Abdelal, A. T. (1999). Role of ArgR in activation of the ast operon, encoding enzymes of the arginine succinyltransferase pathway in Salmonella typhimurium. J Bacteriol 181, 1934-1938.

Lu, C. D., Yang, Z. \& Li, W. (2004). Transcriptome analysis of the ArgR regulon in Pseudomonas aeruginosa. J Bacteriol 186, 3855-3861.

Maas, W. K. (1994). The arginine repressor of Escherichia coli. Microbiol Rev 58, 631-640.

Maghnouj, A., Sousa Cabral, T. F., Stalon, V. \& Vander, W. C. (1998). The $\operatorname{arc} A B D C$ gene cluster, encoding the arginine deiminase pathway of Bacillus licheniformis, and its activation by the arginine repressor argR. J Bacteriol 180, 6468-6475.

Maghnouj, A., Abu-Bakr, A. A., Baumberg, S., Stalon, V. \& Vander, W. C. (2000). Regulation of anaerobic arginine catabolism in Bacillus licheniformis by a protein of the Crp/Fnr family. FEMS Microbiol Lett 191, 227-234.

Makarova, K. S., Mironov, A. A. \& Gelfand, M. S. (2001). Conservation of the binding site for the arginine repressor in all bacterial lineages. Genome Biol 2, RESEARCH0013.

Mercenier, A., Simon, J. P., Haas, D. \& Stalon, V. (1980). Catabolism of L-arginine by Pseudomonas aeruginosa. J Gen Microbiol 116, 381389.

Münch, R., Hiller, K., Grote, A., Scheer, M., Klein, J., Schobert, M. \& Jahn, D. (2005). Virtual footprint and PRODORIC: an integrative framework for regulon prediction in prokaryotes. Bioinformatics 21, 4187-4189.

Park, S. M., Lu, C. D. \& Abdelal, A. T. (1997). Cloning and characterization of $\arg R$, a gene that participates in regulation of arginine biosynthesis and catabolism in Pseudomonas aeruginosa PAO1. J Bacteriol 179, 5300-5308.

Rimmele, M. \& Boos, W. (1994). Trehalose-6-phosphate hydrolase of Escherichia coli. J Bacteriol 176, 5654-5664.

Rosenkranz, M., Elsner, H. A., Sturenburg, H. J., Weiller, C., Rother, J. \& Sobottka, I. (2003). Streptococcus suis meningitis and septicemia contracted from a wild boar in Germany. J Neurol 250, 869-870.

Ryan, S., Begley, M., Gahan, C. G. \& Hill, C. (2009). Molecular characterization of the arginine deiminase system in Listeria monocytogenes: regulation and role in acid tolerance. Environ Microbiol 11, 432-445.

Sambrook, J., Fritsch, E. F. \& Maniatis, T. (1989). Molecular Cloning: a Laboratory Manual, 2nd edn. Cold Spring Harbor, NY: Cold Spring Harbor Laboratory.

Saulnier, D. M. A., Molenaar, D., de Vos, W. A., Gibson, G. R. \& Kolida, S. (2007). Identification of prebiotic fructooligosaccharide metabolism in Lactobacillus plantarum WCFS1 through microarrays. Appl Environ Microbiol 73, 1753-1765.

Smith, H. E., Wisselink, H. J., Vecht, U., Gielkens, A. L. J. \& Smits, M. A. (1995). High-efficiency transformation and gene inactivation in Streptococcus suis type-2. Microbiology 141, 181-188.

Smith, H. E., Damman, M., van der Velde, J., Wagenaar, F., Wisselink, H. J., Stockhofe-Zurwieden, N. \& Smits, M. A. (1999). Identification and characterization of the cps locus of Streptococcus suis serotype 2: the capsule protects against phagocytosis and is an important virulence factor. Infect Immun 67, 1750-1756.

van den Hoff, M. J., Jonker, A., Beintema, J. J. \& Lamers, W. H. (1995). Evolutionary relationships of the carbamoylphosphate synthetase genes. J Mol Evol 41, 813-832.

Willemoës, M. \& Kilstrup, M. (2005). Nucleoside triphosphate synthesis catalysed by adenylate kinase is ADP dependent. Arch Biochem Biophys 444, 195-199.

Winterhoff, N., Goethe, R., Gruening, P., Rohde, M., Kalisz, H., Smith, H. E. \& Valentin-Weigand, P. (2002). Identification and characterization of two temperature-induced surface-associated proteins of Streptococcus suis with high homologies to members of the arginine deiminase system of Streptococcus pyogenes. J Bacteriol 184, 6768-6776.

Zeng, L., Dong, Y. \& Burne, R. A. (2006). Characterization of cisacting sites controlling arginine deiminase gene expression in Streptococcus gordonii. J Bacteriol 188, 941-949.

Zuñiga, M., Miralles, M. C. \& Perez-Martinez, G. (2002a). The product of $\operatorname{arcR}$, the sixth gene of the arc operon of Lactobacillus sakei, is essential for expression of the arginine deiminase pathway. Appl Environ Microbiol 68, 6051-6058.

Zuñiga, M., Perez, G. \& Gonzalez-Candelas, F. (2002b). Evolution of arginine deiminase (ADI) pathway genes. Mol Phylogenet Evol 25, 429-444.

Edited by: H. Ingmer 